\title{
Study of Hollow ZnO Nanoparticles by Flame Spray Synthesis
}

Li Hui ( $D$ Izlihui@163.com )

Xijing University, Shannxi Engineering Research Center of Controllable Neutron Source

\section{Research Article}

Keywords: hollow ZnO, nanoparticles, optical properties

Posted Date: July 24th, 2021

DOl: https://doi.org/10.21203/rs.3.rs-736838/v1

License: (c) (i) This work is licensed under a Creative Commons Attribution 4.0 International License. Read Full License 


\title{
Study of hollow ZnO nanoparticles by flame spray synthesis
}

\author{
Li Hui \\ .Xijing University, Shannxi Engineering Research Center of Controllable Neutron Source, Xi`an, 710123; \\ Correspondent: Li Hui, Tel: 15339119713, E-mail: lzlihui@126.com
}

\begin{abstract}
Hollow $\mathrm{ZnO}$ nanoparticles prepared by flame spray synthesis(FSP) have been reported in this letter. By the results obtained from X-Ray diffraction(XRD) pattern and high-resolution transmission electron microscopy(HR-TEM) picture, it is concluded that the hollow $\mathrm{ZnO}$ nanoparticles were successfully synthesized at high temperature. The size of hollow nanoparticles distributed between 20 and $30 \mathrm{~nm}$, and the formation mechanism of this hollow structure was discussed in the synthesis process. The strong ultra-visible(UV) emission was shown in photoluminescence(PL) spectra, while the mechanism had been explained in detail.
\end{abstract}

Keywords: hollow $\mathrm{ZnO}$, nanoparticles, optical properties

\section{Introduction}

Due to its broad band-gap energy, lost effective, physicochemical stability, easiness of availability and high oxidative capacity, $\mathrm{ZnO}$ based nanocoposites have received much attention in the last decades. Owing to their low density, large outer-and-inner surface as well as cavity-confined nanoscale reactions and transport process, $\mathrm{ZnO}$ nanostructures have wide potential application in the areas of photocatalyst, anti-bacteria, biomedical diagnosis, air ventilation and water purification[1-8].

Enviromental pollution has become a major challenge for the development of modern human society so the waste water treatment utilizing environmental friendly photopcatalysts has been extensively studied. In order to explore the potential of $\mathrm{ZnO}$ nanostructure materials, crystalline morphology, orientation and surface architecture of nanostructure can be well controlled during the preparation process. The simplest hollow nanostructures are $\mathrm{ZnO}$ nanotubes shells and nanoparticles[4,7]. Until now, it was proposed many useful methods for synthesis $\mathrm{ZnO}$ nanoparticles. Since Wong et al. showed the quantum confinement of photoluminescence in $\mathrm{ZnO}$ nanoparticles by electrophoretic deposition (EPD)[9], Usui et al. investigated the defect emission of $\mathrm{ZnO}$ nanoparticles using different surfactant by laser ablationand Demangeot et al. reported the UV emission potential of $\mathrm{ZnO}$ nanoparticles by using organometallic method[10,11]. By these synthesis methods, the size of nanoparticles distributed within a range between several nanometers to several hundreds nanometers. At the same time, our group developed the technique of flame spray synthesis and made some progress on the research of optical properties of undoped, $\mathrm{Mg}$ and $\mathrm{In}$ doped $\mathrm{ZnO}$ nanoparticles[12], based on 
the work of T. Tani who grew metal-oxide nanoparticles with high melting point by flame spray synthesis $[13,14]$. Otherwise, the hollow nanoparticles prepared by flame spray synthesis have rarely been reported. In this paper, we prepared hollow $\mathrm{ZnO}$ nanoparticles by the improved flame spray apparatus and discussed the formation mechanism of hollow $\mathrm{ZnO}$ nanoparticles at high temperature.

On the other side, although $\mathrm{ZnO}$ material has large binding exciton energy of $60 \mathrm{meV}$, the luminescent mechanism of $\mathrm{ZnO}$ nanoparticles is still a controversial issue for optical device. The luminescence was strongly depended on crystalline size[15-16], surface oxygen-related defects and some impurities in the nanoparticles [17-19]. These different factors will result in the intensity of UV emission weak and suppressed at room temperature. Therefore, the optical properties of hollow $\mathrm{ZnO}$ nanoparticles are also currently of great scientific and technical significance. In this paper we will also discuss photoluminescence of the sample.

\section{Experiment}

The schematic of improved apparatus is shown in Figure.1. In the synthesis process, it was used hydrogen gas as combustible gas instead of common gas such as methane or acetylene, which could avoid the formation of carbide impurities at the surface of nanoparticles. The selected precursors mixture was zinc acetate $\left[\mathrm{Zn}\left(\mathrm{CH}_{3} \mathrm{COOH}\right)_{2} \cdot 2 \mathrm{H}_{2} \mathrm{O}, \mathrm{ZnAc} \cdot 2 \mathrm{H}_{2} \mathrm{O}\right]$ which was dissolved in ionized water stirring for $3 \mathrm{~h}$ at room temperature. The solution of $0.05 \mathrm{~mol} / \mathrm{L}$ was set into an ultrasonic sprayer, which substituted common syringe in flame spray pyrolysis of former papers. The preparation process is as follow: A vapor stream carrying $\mathrm{ZnAc}_{2} \cdot 2 \mathrm{H}_{2} \mathrm{O}$ was continuously introduced into a nozzle, combusting in the oxyhydrogen flame $\left(\mathrm{H}_{2}: \mathrm{O}_{2}=2: 1\right.$, the increasing ratio of hydrogen to oxygen could get higher temperature in the inner flame).

A vertical quartz tube was placed onto oxyhydrogen flame to collect the combusted sample. The precursors burning in outer flame deposited in Deposition A, which was composed of solid $\mathrm{ZnO}$ nanoparticles, and the morphology picture was same as the sample previously reported ${ }^{(12)}$. In the top of tube, the samples in this paper deposited in Deposition B where a water cooler was equipped with.

The structures were obtained by X-Ray diffraction (Rigaku D/Max-IIIC CuKa ray), and the morphology of samples were investigated by high-resolution field emission transmission electron microscopy (TEM, Tecani F30 from FEI Company).The photoluminescence(PL) spectra were performed using a UV He-Cd laser excitation source with $325 \mathrm{~nm}$ wavelength at room temperature (300K).

\section{Results and discussion}

Figure.2 presents the XRD patterns of hollow $\mathrm{ZnO}$ nanoparticles by flame spray synthesis deposited in Deposition B. The sharp diffraction peaks matched well with the pattern of standard hexagonal structure of 
$\mathrm{ZnO}$ nanoparticles. The most strong peaks locating at $31.58^{\circ}, 34.62^{\circ}$ and $36.02^{\circ}$ are seen clearly in the XRD pattern of $\mathrm{ZnO}$ nanoparticles, which were corresponding to the (100), (002) and (101) directions of $\mathrm{ZnO}$, respectively. Except for three most obvious peaks, the other peaks contained (102), (110), (103), (200), (112), (201), (004) and (202) of $\mathrm{ZnO}$ could be indexed from the hexagonal $\mathrm{ZnO}$ XRD pattern of JCPDS. According to the Bragger Law, the calculated lattice constant $a$ is $0.3268 \mathrm{~nm}$ and $c$ is $0.5231 \mathrm{~nm}$. By the Scherrer formula, the grain size is evaluated around $25 \mathrm{~nm}$ in different directions of (100) and (101).

Figure. 3 depicts the TEM pictures of samples deposited in Deposition B, where it was equipped a water cooler. As shown in Figure.3, the samples were all nearly composed of hollow nanoparticles with the size of $20 \mathrm{~nm}$, which were different from the solid nanoparticles by flame spray synthesis in the former report ${ }^{(12)}$. By the microbeam electron diffraction (MBED) pattern, it could be seen in the insert figure that the surface of hollow particle was in the direction of (100) and (101), which was consistent with the result of $\mathrm{ZnO}$ XRD pattern.

Compared with the nanoparticles formed in other paper in Deposition A, it was just briefly discussed the formation mechanism of $\mathrm{ZnO}$ hollow nanoparticles. As shown in Figure.4, the $\mathrm{ZnAc}_{2} \cdot 2 \mathrm{H}_{2} \mathrm{O}$ was firstly dissolved in deionized water, and small $\mathrm{Zn}^{2+}$ was formed in water stirring for some while. Along with the vapor steam by ultrasonic sprayer, small $\mathrm{Zn}^{2+}$ droplet was transported into the oxyhydrogen flame. Because the combusting temperature was lower in out flame than that of inner flame temperature, the tiny particles formed $\mathrm{ZnO}$ nanoparticles after undergoing reaction with oxygen. Then, the $\mathrm{ZnO}$ nanoparticles aggregated firmly to form clusters and deposit in Deposition A, where the morphology of nanoparticles could be found in previous paper $^{(12)}$. Some small $\mathrm{Zn}^{2+}$ combusted in inner flame, where the highest temperature of oxyhydrogen flame can reach at $3000 \mathrm{~K}$. Higher temperature was in favor of the reacted $\mathrm{ZnO}$ expending to form hollow sphere structure, which deposited in Deposition B of Figure.1. The morphology was reflected in the TEM picture. There was some possibility that there was some $\mathrm{Zn}^{2+}$ not reacting with oxygen in short time, which was surrounded by $\mathrm{ZnO}$ tiny particles and deposited in the top of tube, whose morphology was corresponding to small solid particles in TEM picture of Figure.3.

We also discussed the PL spectra of hollow nanoparticles measured at room temperature in Figure.5. Firstly, it was explained the weak visible emission. It was found that the weak visible emission was located at around the wavelength of $550 \mathrm{~nm}$. In the previous paper, it was attributed to oxygen vacancy $\left(\mathrm{V}_{\mathrm{O}}\right)$ or znic interstitial $\left(\mathrm{Zn}_{\mathrm{i}}\right)$ when the sample was short of oxygen content in the preparation process ${ }^{(12)}$. As the ratio of hydrogen to oxygen increased $\left(\mathrm{H}_{2}: \mathrm{O}_{2}=1: 1\right.$ and $\left.\mathrm{H}_{2}: \mathrm{O}_{2}=2: 1\right)$, the combusted temperature increased in the inner flame especially. However, when the morphology of particle changed from solid into hollow in the same size range, the location 
of visible emission didn't change to some extent. In the former reports, there were also reported a broad visible emission located $550 \mathrm{~nm}$, which was originated from the $\mathrm{V}_{\mathrm{O}}$ located near the surface region ${ }^{(18,20)}$. In our experiment, the location of visible emission was same as the results of them. This result was different from other defects discussion on visible emission of $\mathrm{ZnO}$ powder and $\mathrm{ZnO}$ nanoparticles in $\mathrm{SiO}_{2}$ by ion implantation combined with thermal oxidation ${ }^{(21-23)}$, where the visible emission usually located around $520 \mathrm{~nm}$. Therefore, it was attributed the $550 \mathrm{~nm}$ emission to surface absorption defects in the size of $20 \mathrm{~nm}$ range after precursors oxidation at room temperature.

The Figure.5 also depicts the near-band-edge (NBE) emission in UV area centered at around the wavelength of $360 \mathrm{~nm}$ (The peak was corresponded with $3.35 \mathrm{eV}$ ). The energy of NBE emission was lower than the band gap (3.38 eV), which was same as that of the solid $\mathrm{ZnO}$ nanoparticles. It was considered that the NBE emission had some relation with exciton emission as same as other papers about $\mathrm{ZnO}$ nanomaterials. Compared with solid nanoparticles, the intensity of hollow nanoparticles increased to some extent, while the intensity of visible emission nearly changed little. On one side, the exciton effect in nano-hollow structures was stronger than that of bulk and film materials at room temperature, and the former structure was in favor of fulfilling exciton emission near the band edge. At low temperature, this prominent effect happened much evident. On the other side, the high temperature of oxyhydrogen flame could decrease the defects adsorbed at the surface of nanoparticles, which usually suppressed the NBE exciton emission. Therefore, in our paper the NBE emission of $20 \mathrm{~nm}$ hollow $\mathrm{ZnO}$ nanoparticles was stronger in evidence than that of other reports.

\section{Conclusion}

The hollow $\mathrm{ZnO}$ nanoparticles were successfully prepared by improved flame spray synthesis at high temperature. High-resolution field emission TEM analysis revealed that the size of hollow particle ranged between 20-30 $\mathrm{nm}$. It was discussed the reason of increasing NBE emission by exciton effects, and weak visible emission by the defects in the surface of hollow nanoparticles produced in the process of preparation.

\section{References}

1. L. L. Chng, N. Erathodiyil, and J. Y. Ying; Nanostructured catalysts for organic transformations; Acc. Chem. Res. 46, 1825 (2013).

2. X. Duan, G. Wang, H. Wang, Y. Wang, C. Shen, and W. Cai; Orientable pore-size-distribution of ZnO nanostructures and their superior photocatalytic activity; Cryst. Eng. Comm. 12, 2821 (2010).

3. T. Sun, J. Qiu, and C. Liang; Controllable fabrication and photocatalytic activity of ZnO nanobelt arrays; J. Phys. Chem. C 112, 715 (2008). 
4. H. Q. Wang, G. H. Li, L. C. Jia, G. Z. Wang, and C. J. Tang; Controllable preferential-etching synthesis and photocatalytic activity of porous ZnO nanotubes; J. Phys. Chem. C 112, 11738 (2008).

5. Y. Zheng, C. Chen, Y. Zhan, X. Lin, Q. Zheng, K. Wei, J. Zhu, and Y. Zhu; Luminescence and photocatalytic activity of $\mathrm{ZnO}$ nanocrystals: Correlation between structure and property; Inorg. Chem. 46, 6675 (2007).

6. D. Wu, Z. Gao, F. Xu, J. Chang, W. Tao, J. He, S. Gao, and K. Jiang; Hierarchical ZnO aggregates assembled by orderly aligned nanorods for dye-sensitized solar cells; Cryst. Eng. Comm. 15, 1210 (2013).

7. X. Lu, G. Wang, S. Xie, J. Shi, W. Li, Y. Tong, and Y. Li; Efficient photocatalytic hydrogen evolution over hydrogenated $\mathrm{ZnO}$ nanorod arrays; Chem. Commun. 48, 7717 (2012).

8. K. Sun, Y. Jing, C. Li, X. Zhang, R. Aguinaldo, A. Kargar, K. Madsen, K. Banu, Y. Zhou, Y. Bando, Z. Liu, and D. Wang; 3D branched nanowire heterojunction photoelectrodes for high efficiency solar water splitting and $\mathrm{H}_{2}$ generation; Nanoscale 4, 1515 (2012).

9. E. M. Wong, P. C. Searson; ZnO quantum particle thin films fabricated by electrophoretic deposition; Appl. Phys. Lett. 74, 2939 (1999)

10. H. Usui, Y. Shimizu, T. Sasaki, N. Koshizaki; Photoluminescence of ZnO nanoparticles prepared by laser ablation in different surfactant solutions; J. Phys. Chem. B 109, 120 (2005)

11. F. Demangeot, V. Paillard, P. M. Chassaing, C. Pages, M. L. Kahn, A. Maisonnat, B. Chaudret; Experimental study of $\mathrm{LO}$ phonons and excitons in $\mathrm{ZnO}$ nanoparticles produced by room-temperature organometallic synthesis; Appl. Phys. Lett. 88, 071921 (2006)

12. H. Li, Z. Zhang, X. Pan, H. Zhang, T. Wang, E. Xie; Effects of In and Mg doping on properties of ZnO nanoparticles by flame spray synthesis; J. Nanopart. Res. 11, 917 (2009)

13. T. Tani, L. Madler, S. E. Pratsinis; Homogeneous $\mathrm{ZnO}$ nanoparticles by flame spray pyrolysis; J. Nanopart. Res. 4, 337 (2002)

14. T. Tani, K. Takatori, S. E. Pratsinis; Evolution of the morphology of zinc oxide/silica particles made by spray combustion; J. Am. Ceram. Soc; 87, 365 (2004)

15. Z. D. Fu, Y. S. Cui, S. Y. Zhang, J. Chen, D. P. Yu, S. L. Zhang, L, Liu, J. Z. Jiang; Study on the quantum confinement effect on ultraviolet photoluminescence of crystalline $\mathrm{ZnO}$ nanoparticles with nearly uniform size; Appl. Phys. Lett. 90, 263113(2007)

16. M. Yoshikawa, K. Inoue, T. Nakagawa, H. Ishida, N. Hasuike, H. Harima; Characterization of ZnO nanoparticles by resonant Raman scattering and cathodoluminescence spectroscopies; Appl. Phys. Lett. 92, 
$113115(2008)$

17. C. Y. Lee, Y. Y. Hui, W. F. Su, C. F. Lin; Electroluminescence from monolayer ZnO nanoparticles using dry coating technique; Appl. Phys. Lett. 92, 261107 (2008)

18. M. Ghosh, A. K. Raychaudhuri; Ionic environment control of visible photoluminescence from $\mathrm{ZnO}$ nanoparticles; Appl. Phys. Lett. 93, 123113 (2008)

19. W. Q. Peng, S. C. Qu, G. W. Cong, Z. G. Wang; Synthesis and temperature-dependent near-band-edge emission of chain-like Mg-doped ZnO nanoparticles; Appl. Phys. Lett. 88, 101902(2006)

20. I. Shalish, H. Temkin, V. Narayanamurti; Size-dependent surface luminescence in ZnO nanowires; Phys. Rev. B 69, 245401 (2004)

21. K. Vanheusden, W. L. Warren, C. H. Seager, D. R. Tallant, J. A. Voigt, B. E. Gnade; Mechanisms behind green photoluminescence in $\mathrm{ZnO}$ phosphor powders; J. Appl. Phys. 79, 7983 (1996)

22. H. Amekura, N. Umeda, Y. Sakuma, N. Kishimoto, C. Buchal; Fabrication of ZnO nanoparticles in SiO2 by ion implantation combined with thermal oxidation; Appl. Phys. Lett.; 87, 013109 (2005)

23. H. Amekura, N. Umeda, Y. Sakuma, O. A. Plaksin, Y. Takeda, N. Kishimoto, C. Buchal; Zn and ZnO nanoparticles fabricated by ion implantation combined with thermal oxidation, and the defect-free luminescence; Appl. Phys. Lett., 88, 153119 (2006)

\section{Figures}

Figure.1. The schematic diagram of flame spray synthesis apparatus.

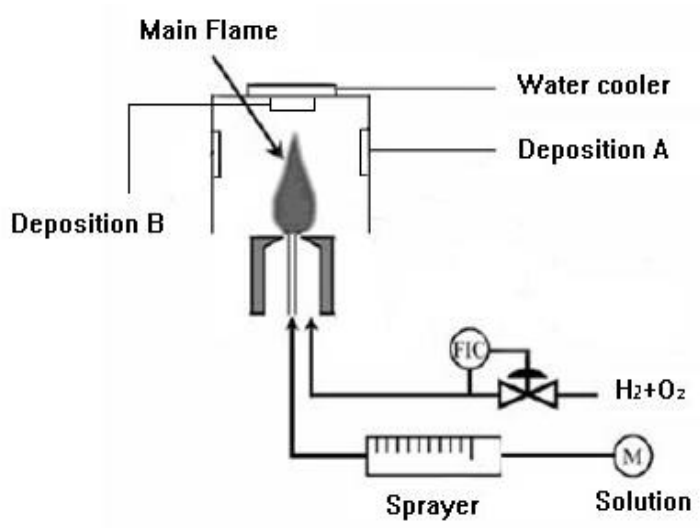

Figure.2. The XRD pattern of hollow $\mathrm{ZnO}$ nanoparticles. 


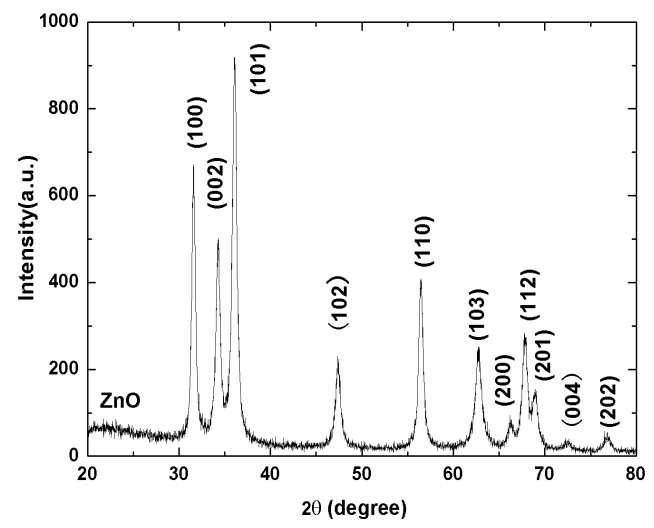

Figure.3. TEM images of hollow $\mathrm{ZnO}$ nanoparticles and corresponding MBED pattern in the insert figure.
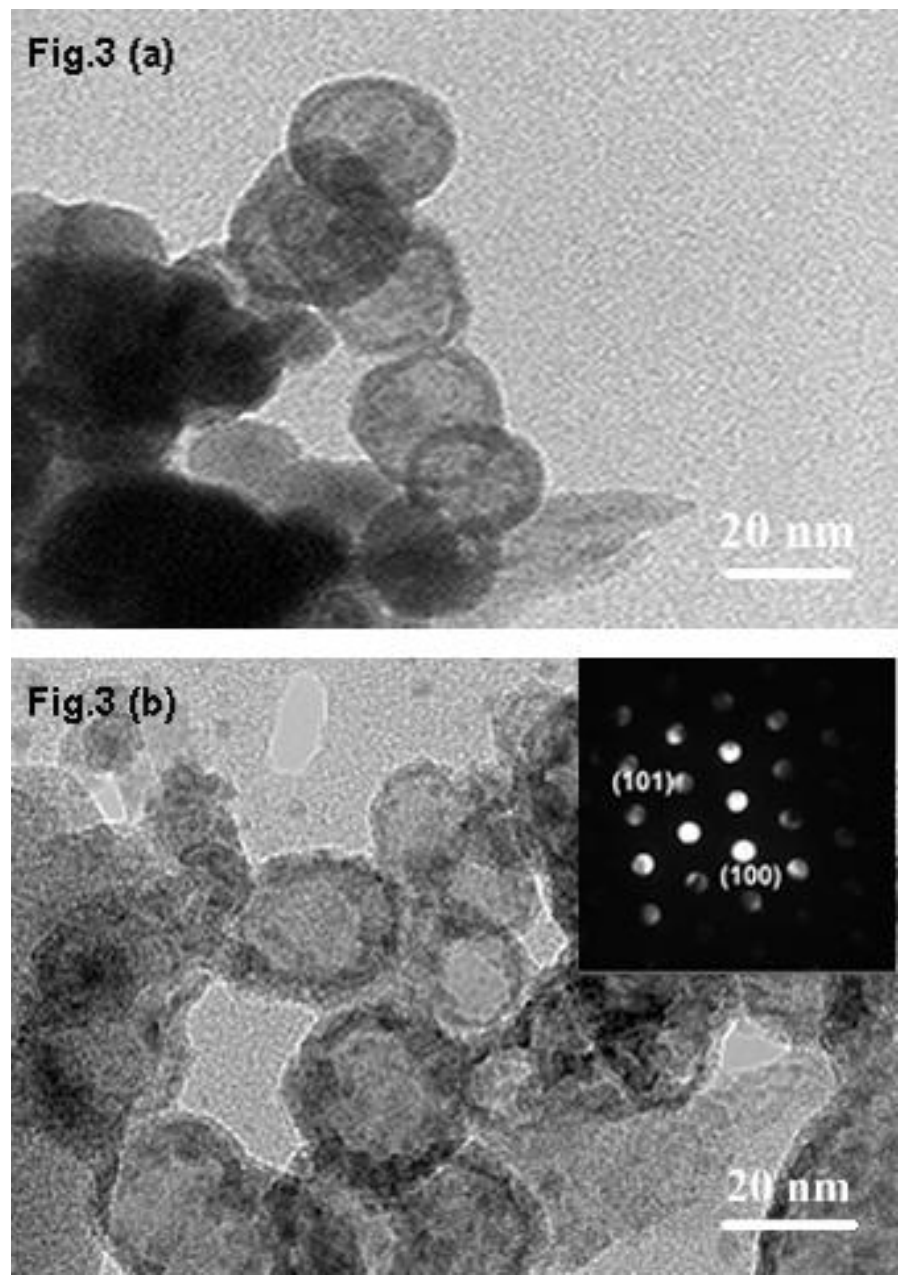

Figure.4. The formation process of hollow $\mathrm{ZnO}$ nanoparticles by flame spray synthesis. 


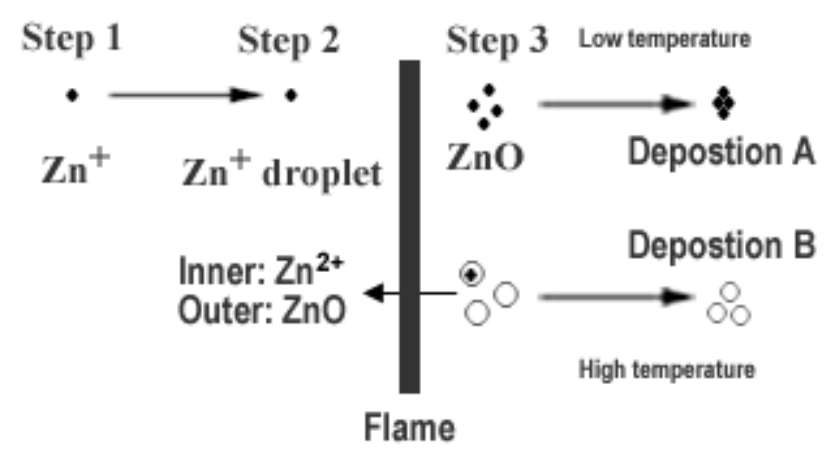

Figure.5. The PL spectra of hollow $\mathrm{ZnO}$ nanoparticles at room temperature.

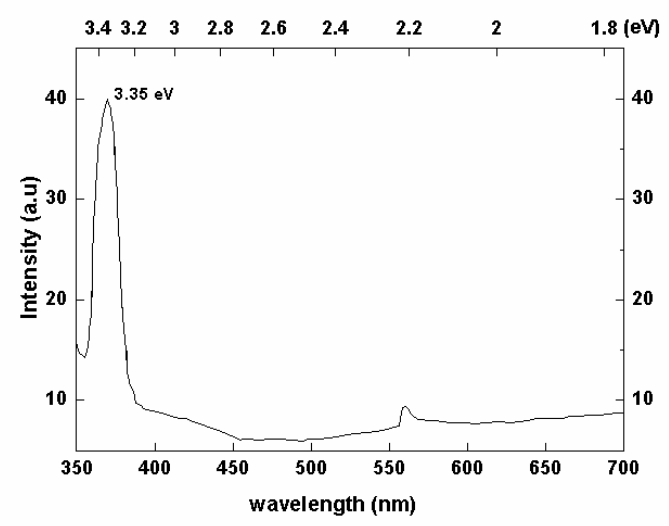

